\title{
Morphological Complexity and Language Contact in Languages Indigenous to North America Marianne Mithun
}

University of California, Santa Barbara

It has long been noticed that morphological complexity is not distributed evenly across the world. There are also well-known geographical pockets of morphological elaboration in areas of Northern Australia, Papua New Guinea, Siberia, and the Caucasus. During the $19^{\text {th }}$ century, Duponceau (1819), Brinton (1886), and Hewitt (1893) pointed to the special complexity of languages of the Americas. But the idea that complex morphological structure should show areal distributions seems counterintuitive: traditional scales of borrowability have typically begun with vocabulary, then moved through phonetics and phonology, and on to syntax, with morphology at the end or not mentioned at all. Such scales would seem to be in line with what we know about domains of structure: morphological structure is distinguished from syntax by its routinization: most of it is below the level of consciousness. Bilinguals should be less likely to transfer individual morphemes or morphological patterns from one of their languages to the other than to transfer whole words or word orders.

One factor underlying the distributions of complexity might be the social circumstances under which the languages are used and transmitted, as proposed by Dahl (2004, to appear) and (Trudgill 2011, to appear). In small, closed communities, where speakers interact with a constant group of native interlocutors who share a common set of presuppositions about the world, culture, and interests, certain expressions are likely to occur more frequently in speech than in larger, more diffuse communities. The frequency can lead to routinization of the recurring sequences and the development of complex morphological structures, with large inventories of lexicalized expressions. But language contact can have an impact on such development. Morphological complexity can be reduced when there is a substantial proportion of untutored adult second-language learners. It can present special challenges for such speakers, leading them to select more analytic alternatives in their speech. With intense contact of certain types, such as when large numbers of adult second-language speakers are raising children, choices made by these speakers can ultimately affect the shape of the language. Contact can also have the opposite effect. In communities with substantial early multilingualism, morphological complexity may be further enriched when speakers draw on the enhanced communicative resources of multiple languages, each with its own complexities, in their daily speech.

Morphological complexity is normally what Dahl has termed a 'mature' phenomenon: it tends to develop gradually over time. But it need not be borrowed in its mature state. Bilinguals may carry less mature structures, such as turns of phrase and even compounding, from one of their languages to another, structures which then continue to develop along common pathways of grammaticalization. Areal parallelisms may originate even earlier in the process. Bilinguals may unconsciously transfer propensities for specifying certain distinctions from one language to another. The resulting frequencies of expression can lead, over time, to parallel routinization and morphologization.

Here some potential effects of both kinds of circumstances, community makeup and contact, are explored for languages indigenous to North America. The general prevalence of morphological complexity on the continent accords at least in part with the absence of heavy adult second-language learning. But the precise nature of the complexity varies across areas, 
suggesting effects of longstanding early multilingualism, with shared attention to certain kinds of semantic specification.

\section{Morphological complexity}

Linguistic complexity has been defined in a number of ways. Dahl (to appear) provides a useful discussion of various approaches. As he points out, one can distinguish relative or agent-related complexity, pertaining to 'the amount of effort a generalized outsider has to make to become acquainted with it' (from Kusters 2003, 2008:9) from absolute or objective complexity, an objective property of a system conceived of in terms of information theory (Dahl 2004, Lindström 2008, Miestamo 2008). One can further distinguish system complexity, pertaining to the language as a whole, from structural complexity, pertaining to the structure of individual utterances and expressions: 'While system complexity concerns competence/langue, structural complexity pertains to performance/parole, since it is about properties of individual utterances' (Dahl to appear). A kind of measure halfway between the two could be corpus complexity, the complexity inherent in a substantial representative sample of the language. Within the sample, one could calculate the morpheme-to-word ratio, or the morpheme-to-word ratio just for verbs, where morphological complexity tends to be concentrated. One could compare the number of distinct word forms, since presumably larger paradigms would result in more word forms, or the total number of words across comparable texts in different languages. One could also compare the number of slots in verbal templates, or of obligatory slots.

Another dimension of complexity discussed by Dahl and others is non-linearity in mapping between content and expression. Non-linearity would include such phenomena as partial or total fusion of morphemes, cumulative or portmanteau expressions, suppletion, dependence on lexical classes, and also prosodic (suprasegmental) features of expression and element order not predictable from hierarchical structure.

The kind of complexity most frequently cited as typical of North America is polysynthesis, particularly the potential for morphologically complex verbs that can function as complete predications in themselves. This is holophrasis in a specific sense, the specification within the verb of both predicate and core arguments (Mithun to appear a, b). Also often associated with polysynthesis is noun incorporation, whereby a noun stem is compounded with a verb stem to form a new stem, adding to the number of morphemes within verbs.

\section{North America}

North America north of Mexico shows tremendous genealogical diversity. It is home to perhaps 275 distinct languages so far as is known, and around 55 genetic groups. A rough impression of the diversity can be grasped from Figure 1, which represents the approximate ranges of tribal territories at the earliest times for which information is available. Divisions between territories are schematic; boundaries were not usually sharp, and not all areas were occupied.

The genealogical groups range in size from large families like Athabaskan-Eyak Tlingit, with 37 languages, to isolates like Zuni, with just one language. Documentation of the languages, many of which are no longer spoken, varies widely. For some there are rich corpora of connected speech, grammars, and detailed dictionaries, while for others, there are only short wordlists, making it difficult to assess morphological structures. 


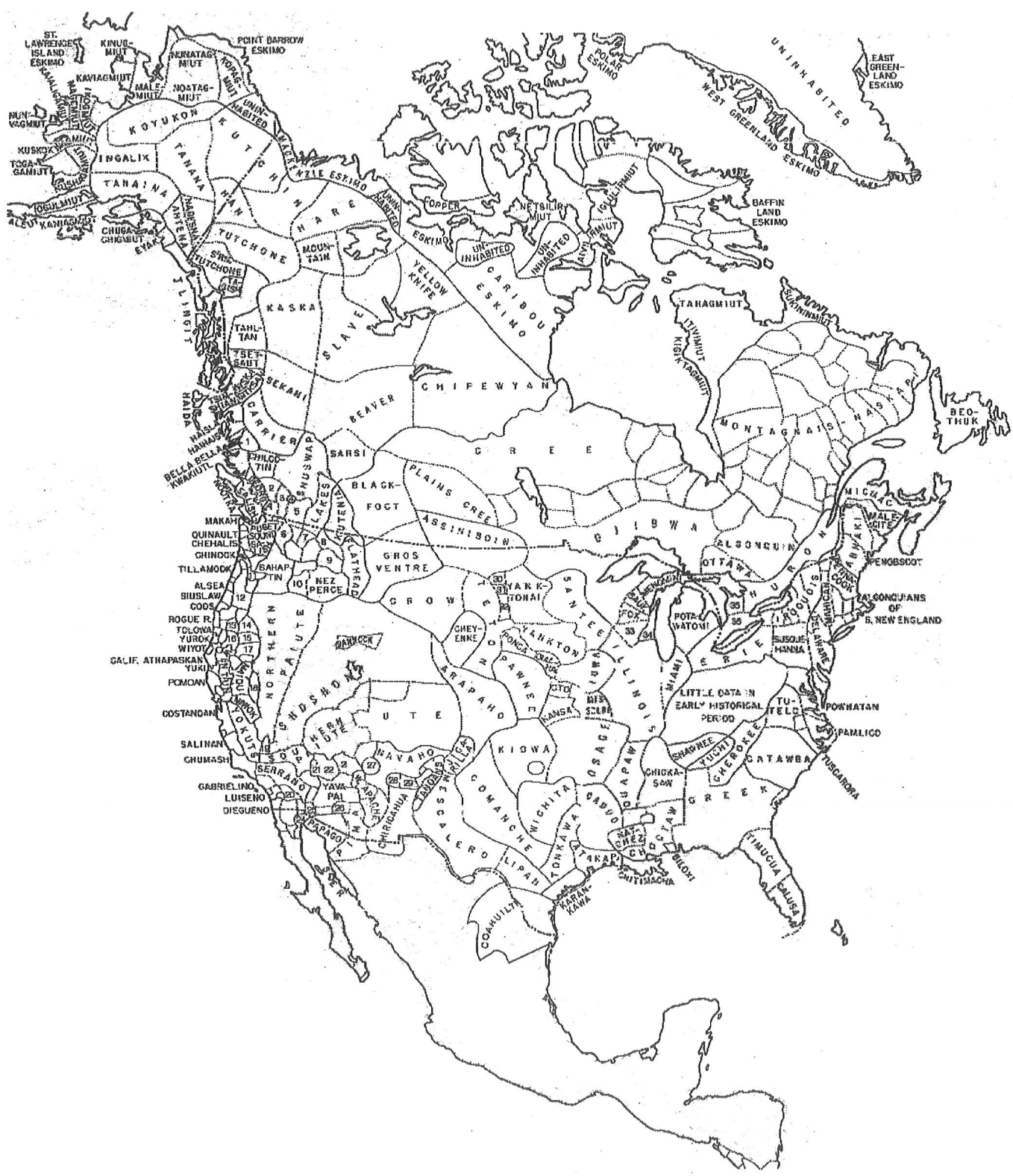

Figure 1. Languages Indigenous to North America

Despite the genealogical diversity, degrees of complexity are not random. Not only is the complexity pervasive, it can also be seen in many cases to be quite stable. Language families whose ancestors can be reconstructed back over millennia, such as Chumashan, Iroquoian, and Eskimo-Aleut, are reconstructed with most of their morphological structures as they are today (Mithun in press, Fortescue, Jacobson, and Kaplan 2010).

\section{Holophrasis}

A majority of the geneaological groups show what has been called head-marking, with core arguments identified in the verb. In some languages, all core arguments are specified: three persons and two or three grammatical roles. In languages of the Chinookan family, spoken along 
the Columbia River between modern Washington and Oregon, first, second, and third persons are distinguished in pronominal prefixes; singular, dual, and plural number; inclusive and exclusive first persons; masculine, feminine, and neuter third persons; and ergative, absolutive, and dative roles.

(1) Wishram: Dyk 1933:77, 73, 74

a. I-y-ú-pa.

IMM.PAST-M.SG.ABS-go-out

'He went out.'

b. I-ť̌s-i-u-táta.

IMM.PAST-M.SG.ERG-M.SG.ABS-away-drag

'He dragged him.'

c. I-y-a-k-łait

IMM.PAST-M.SG.ABS-F.SG.DAT-on-sit

'He sat on her.'

Figure 2 provides a general idea of the distribution of languages with all core arguments marked, in three persons or more.

But overt specification of all arguments is not ubiquitous. Very often one or more third persons are unmarked, perhaps singulars, just subjects, just objects, non-humans, inanimates, or indefinites. Details of such differential argument marking vary from language to language. Sapir provides the paradigm below from Takelma, an isolate earlier spoken in southwestern Oregon.

(2) Takelma: Sapir 1922: 165

$\begin{array}{ll}\begin{array}{ll}\text { haná?s-de? } \\ \text { haná?s-dam }\end{array} & \begin{array}{l}\text { 'I stop' } \\ \text { 'you stop' }\end{array} \\ \begin{array}{ll}\text { haná?s-ik } \\ \text { haná?s-dap }\end{array} & \begin{array}{l}\text { 'we stop' } \\ \text { haná?s }\end{array} \\ \end{array}$

Here there is no third person suffix.

In transitive verbs, object suffixes can be seen to precede subject suffixes except when first persons act on second (1>2). Object suffixes are 1SG-xi, 2SG-bi, 1PL -am, and 2PL -anp. Third person human objects are optionally indicated by a suffix $-k^{h} w a /-g w a$ when combined with third person subjects, but third person non-humans are unmarked.

(3) Takelma: Sapir 1922:168

i:t'anáha-gwa 'he held him'

i:t'anáhi 'he held it' 


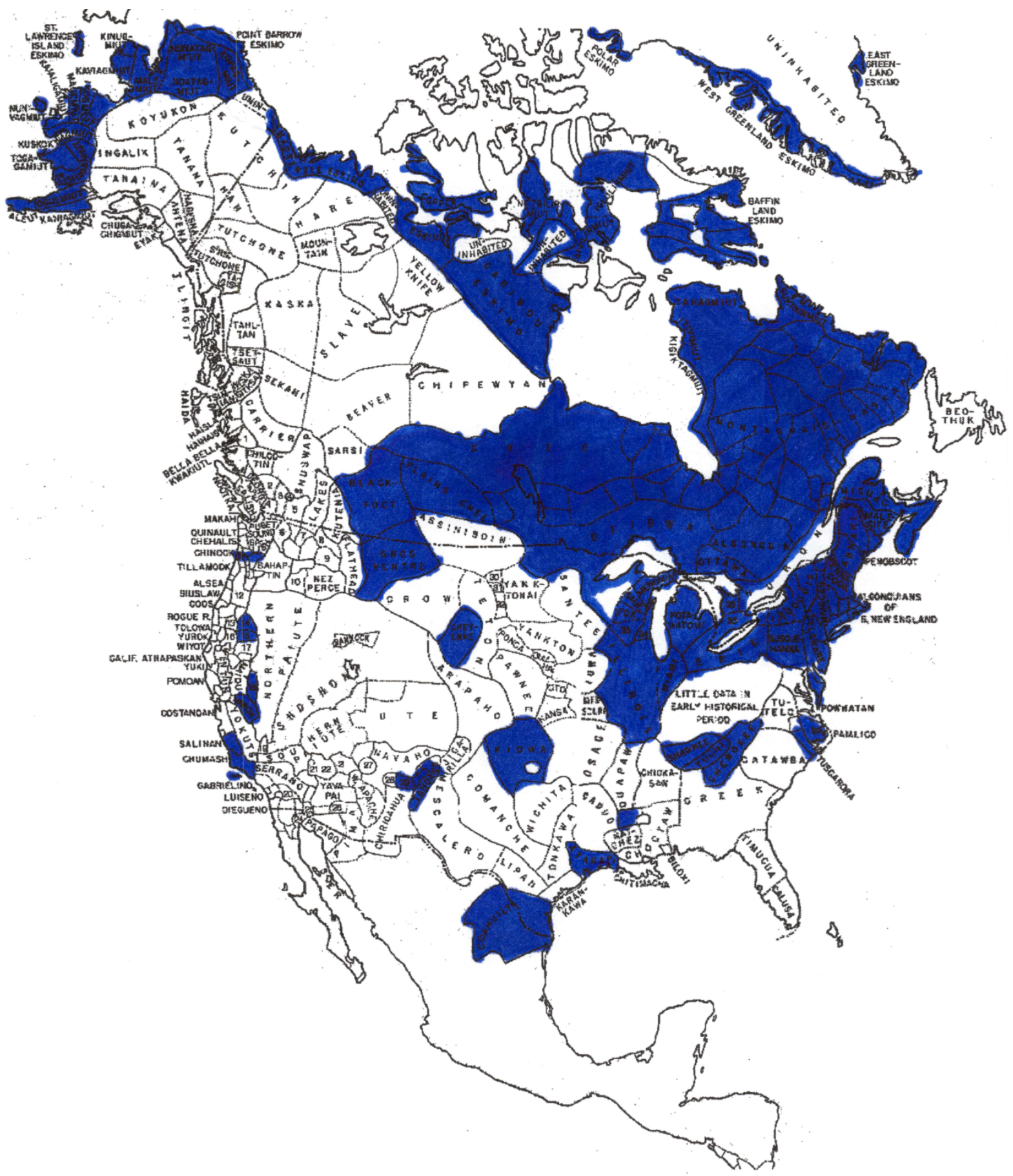

Figure 2. Languages with All Core Arguments in Three Persons in the Verb

Differential argument marking can show other patterns as well. In some languages, one set of core arguments is identified by affixes and another by clitics. In the Tsimshianic languages of British Columbia, for example, absolutives are indicated by verbal suffixes, but ergatives by clitics showing complex patterns. Figure 3 provides a general idea of the distribution of languages with differential marking of various types. 


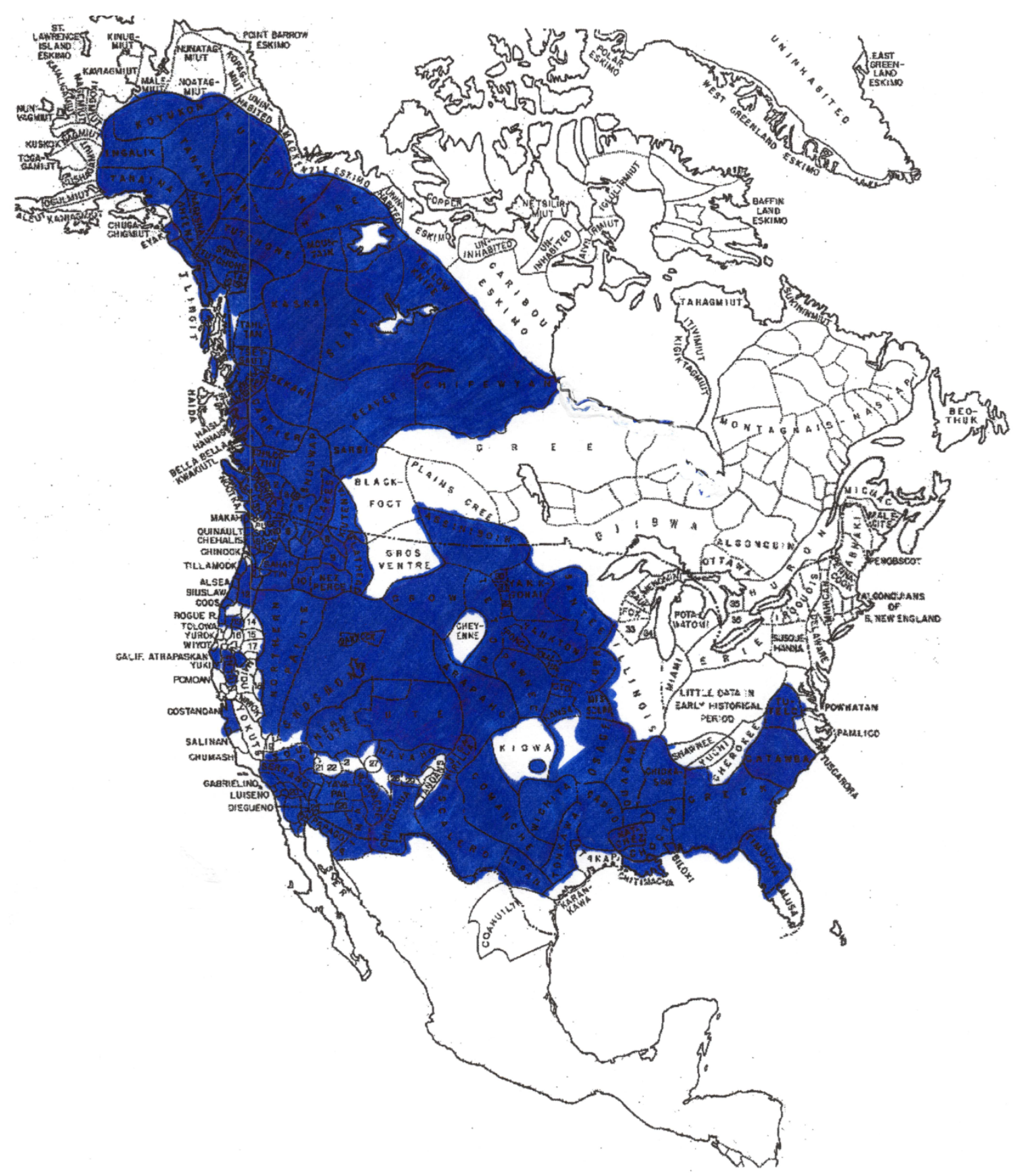

Figure 3. Pronominal Reference to Subsets of Core Arguments in the Verb

As can be seen by comparing Figures 2 and 3, head-marking is pervasive in North America. In fact the languages lacking such marking are few and far between, as can be seen in Figure 4. 


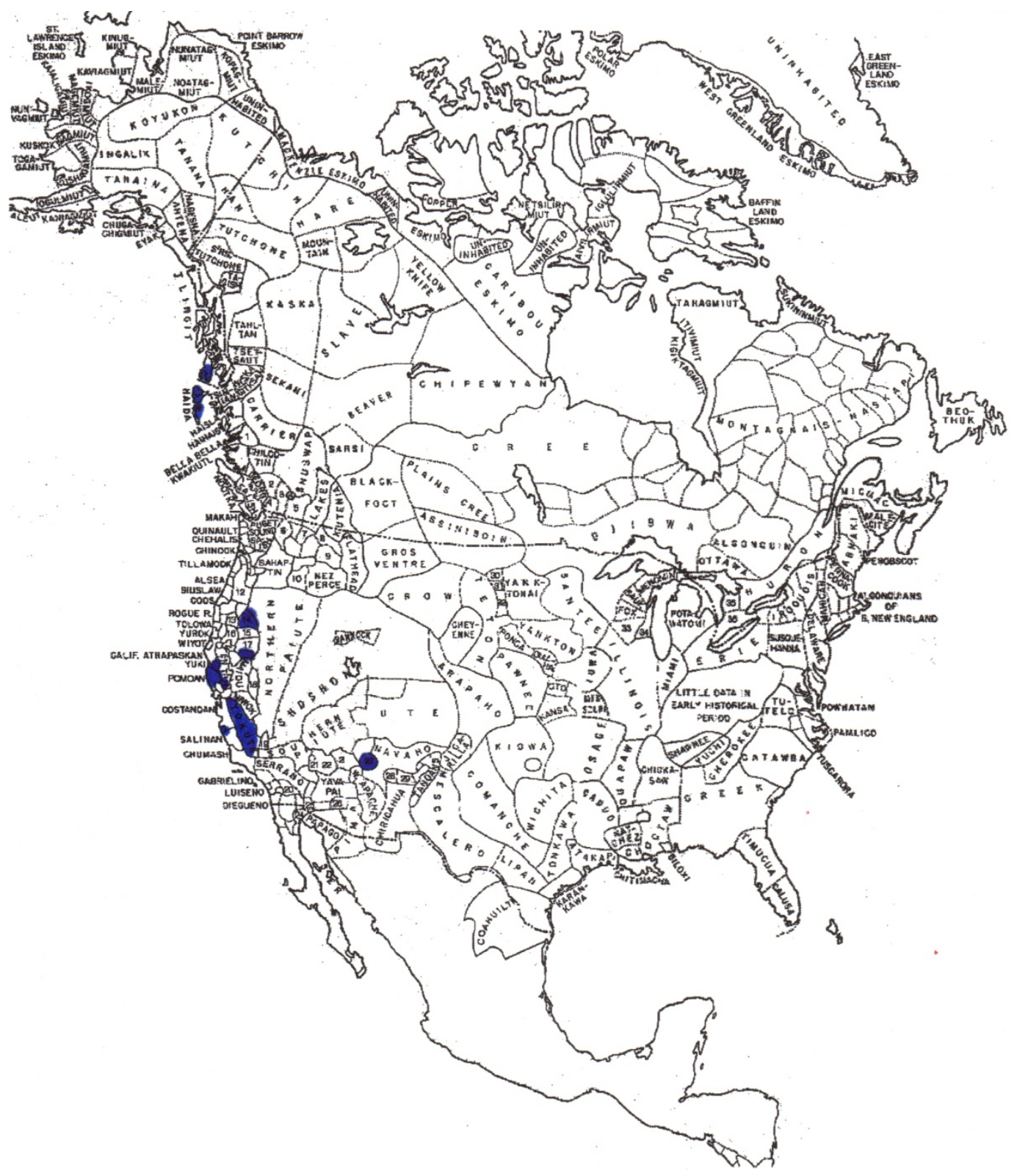

Figure 4. Languages without Bound Pronouns

The development of pronominal affixes within the verb is not surprising, given the kinds of recurring processes which create morphological structure. Unstressed pronouns, representing given participants, are highly frequent in speech. Their frequency, their frequent position adjacent to the verb, and their lack of stress make them ripe for phonological reduction and ultimate fusion with the verb. It is also not surprising that third persons, or inanimate third persons, etc., should be the last to develop into affixes. While first and second persons are 
overwhelmingly given referents in speech, and thus normally represented by unstressed pronouns, third persons may be given, or simply accessible, or brand new. They are thus variously represented by unstressed pronouns, demonstratives, lexical nouns, proper names, or larger determiner phrases. Human third persons are more likely to be continuing topics than nonhumans, and animates more likely than inanimates, so it is not surprising that some languages would have pronominal affixes referring to humans or animates but not non-humans or inanimates. In many languages continuing third person topics are not mentioned overtly at all, so there would be no unstressed pronominal form to bond with the verb.

Pronominal affix paradigms can be complex in ways that independent pronouns are not. Sapir (1922:159) notes that every Takelma verb has six tense-mode paradigms. All but one have their own sets of pronominal endings. There are in addition distinct paradigms for the two main classes of intransitive verbs and for transitive verbs. Sapir lists eleven pronominal paradigms: aorist subject intransitive I, aorist subject intransitive II, aorist subject transitive, future subject intransitive I, future subject intransitive II, future subject transitive, inferential subject, present imperative subject, future imperative subject intransitive I and transitive, future imperative subject intransitive II, and object transitive and passive subject. The forms are further subject to various phonological processes.

Complexity of this sort apparently presents children immersed in their mother tongue with little serious difficulty: languages with such structures have endured for millennia. For adult learners, however, it can be daunting, and their language is likely to show simplification. Trudgill (2011, to appear) hypothesizes that when the proportion of adult second-language learners passes $50 \%$, such simplification can leave a mark on the language itself, providing a kind of brake on the development of complexity. But without large numbers of adult learners, complexity could develop largely uninhibited. Such an account would accord with the widespread head marking across North America. There are few clear records of the nature of language contact in North America beyond the past several centuries, but for the most part, evidence is slim of widespread adult second-language acquisition. In some areas, relatively small groups speaking a single language occupied large territories. In other areas, communities were small and in closer contact, but exogamy and multilingualism were the norm, so that children learned neighboring languages early and used them throughout their lives. In general, nearly all of the pronominal affix systems found in languages indigenous to North America continue systems already present in their reconstructed parent languages.

\section{Noun Incorporation}

Another frequently-cited contributor to morphological complexity is noun incorporation, a word formation process of noun-verb or verb-noun compounding that creates complex verb stems. Noun incorporation is pervasive in North America, but it varies in the extent of its development and its productivity.

\subsection{Basic Noun Incorporation}

Examples of contrasting analytic and incorporating constructions are in (4) from Crow, a Siouan language of Montana. 
(4) Crow incorporation: Graczyk 2007:280
$\begin{array}{lll}\text { a. Iisáakshe } & \text { íliiia } & \text { daxxóxx-uu-k. } \\ \text { young.men } & \text { tipi.poles } & \text { peel-PL-DECL }\end{array}$
'The young men peeled the tipi poles' (the ones they cut in the mountains yesterday)
b. Iisáakshe íilii-daxxoxx-uu-k.
young.men tipi.poles-peel-PL-DECL
'The young men were peeling tipi poles.' (engaging in the activity of peeling poles)

As Graczyk notes, 'the combination of verb plus incorporated object conveys the notion that the subject is engaged in a customary, habitual, or repeated activity, or a habitual mental state. Incorporation can even occur when a single action is referred to, as long as the object is nonspecific' (2007:280). There is no question that the noun-verb combination in (4b) constitutes a single word: it contains just one stress and there is no possibility of pause between the constituents.

The semantic relation between the incorporated noun and verb is not specified by the construction, but the noun generally qualifies the verb in some way, often indicating a kind of semantic patient, theme, or goal ('pole-peel'), or an instrument or location. Additional examples of Crow verb stems formed by incorporation cited by Graczyk include 'ask for money'; 'speak Crow'; 'dislike Crows'; 'ride horseback'; 'steal horses'; 'drink water'; 'make soup'; 'fight fire'; 'wash berries'; 'climb trees'; 'catch fish'; watch TV'; 'look for food'; 'go into the sweat lodge'; 'tell a dream'; 'fix fence'; and 'put up a tipi'.

The functions of incorporation vary across languages. In all languages where it occurs, it generally serves as a word-formation device, creating terms for generic activities and recurring situations as in the Crow example above. It may affect argument structure, as in (5).

(5) Crow incorporation: Graczyk 283

$\begin{array}{llll}\text { Áappaa } & \text { piakálaa-m } & \text { dappii-ák } & \text { aashúu-lutchi-k. } \\ \text { also } & \text { Piegan-DET } & \text { kill-SAME.SUBJECT } & \begin{array}{l}\text { head-take-DECL } \\ \text { 'Also, }\end{array}\end{array}$

'Also, he killed a Piegan and scalped him.'

The incorporation of the noun 'head' allows the speaker to cast the victim rather than his head as a core argument: 'he scalped him' rather than 'he took his scalp'. In a great many languages, among the most frequently-incorporated nouns are terms for body parts. Some additional Crow formations involving body parts include ishtá-xia 'eye-dim' = 'be nearsighted', ahkúx-alee 'earache' = 'have an earache', éel-isaa 'belly-be.big' = 'be pregnant', and iishpuu-xachii 'stomachmove' = 'have stomach cramps' (Graczyk 2007:282).

In some languages noun incorporation is also used to manage the flow of information through discourse. Referents are first introduced in separate words or phrases, then subsequently carried along less obtrusively by noun stems incorporated into verbs. In some languages incorporation constructions are also used as presentatives, with a noun incorporated into a light verb of position, arrival, etc.

In some languages noun incorporation is pervasive and highly productive, while in others it is more limited. In some it is no longer productive, but formations remain in the lexicon, products of an earlier process. Traces of incorporation can be seen in Cherokee, an Iroquoian 
language spoken in North Carolina and Oklahoma. A number of modern verb stems show variation at the beginning according to the kind of entity involved.

(6) Cherokee: Feeling 1975: 195-6

$\begin{array}{ll}\text { asul-a?iyv?-a } & \text { 'he changed his pants' } \\ \text { ahnaw-a?iyv?-a } & \text { 'he changed his shirt' } \\ \text { dahnaw-a?iyv?-a } & \text { 'he changed clothes' } \\ \text { dalasul-a?iyv?-a } & \text { 'he changed his shoes' }\end{array}$

All of these verbs contain identifiable prefixes and suffixes. The prefix $a$ - is a third person agent pronominal prefix. The prefix $d$ - is a distributive, cognate with the Northern Iroquoian duplicative. Here it indicates actions involving multiple articles of clothing. The final suffix $-a$ marks progressive or immediate past action. All of these verb stems involving changing end in -aPiyv?-. The initial elements of these stems appear to be relicts of earlier incorporated nouns, but these are now considered simply separate verb stems. In all other Iroquoian languages, noun incorporation remains robust: productive and pervasive. Noun incorporation or relicts of a once productive process are widespread across North America, as can be seen in Figure 5.

\section{2. "Lexical affixes"}

Productive noun incorporation constructions are not necessarily static. They can undergo further development into productive affixation. Very early stages of such development can be seen in Algonquian languages, spoken across the continent from the Plains to the Atlantic Ocean. Algonquian verb stems are traditionally described as composed of up to three main parts, termed initials, medials, and finals. All stems contain an initial and a final. Initials generally convey meanings similar to verb roots in other languages, denoting events and states. Abstract finals add more grammatical meanings, specifying argument structure (transitive, intransitive, causative, reflexive, middle, passive), etc., though there are also derived finals with more concrete meanings.

Medial suffixes, which are not obligatory, are in many ways similar to incorporated nouns in other languages. They often evoke generic entities that qualify the verb in some way, often as patients/goals/themes, like 'fish' in the Innu example in (7). Like incorporated nouns in many languages, they often evoke body parts. Also like incorporated nouns in many languages, they can be more general and abstract then lexical nouns. They can serve a classificatory function, evoking a general type of entity, such as 'sheet-like object' or 'organic, solid, non-flexible objects, etc.

(7) Innu (Montagnais) Medial: Lynn Drapeau, p.c.

Matineumesheu nutaui.

ma:tənwe:-me:š-e:w n-uta:wi:

share-fish-FIN.AI-3 1-father

'My father shares out fish.'

Drapeau (2014) has identified around 200 common medials, some of which have the form of full nouns, some bound alternants of independent nouns, and a number of other bound morphemes 


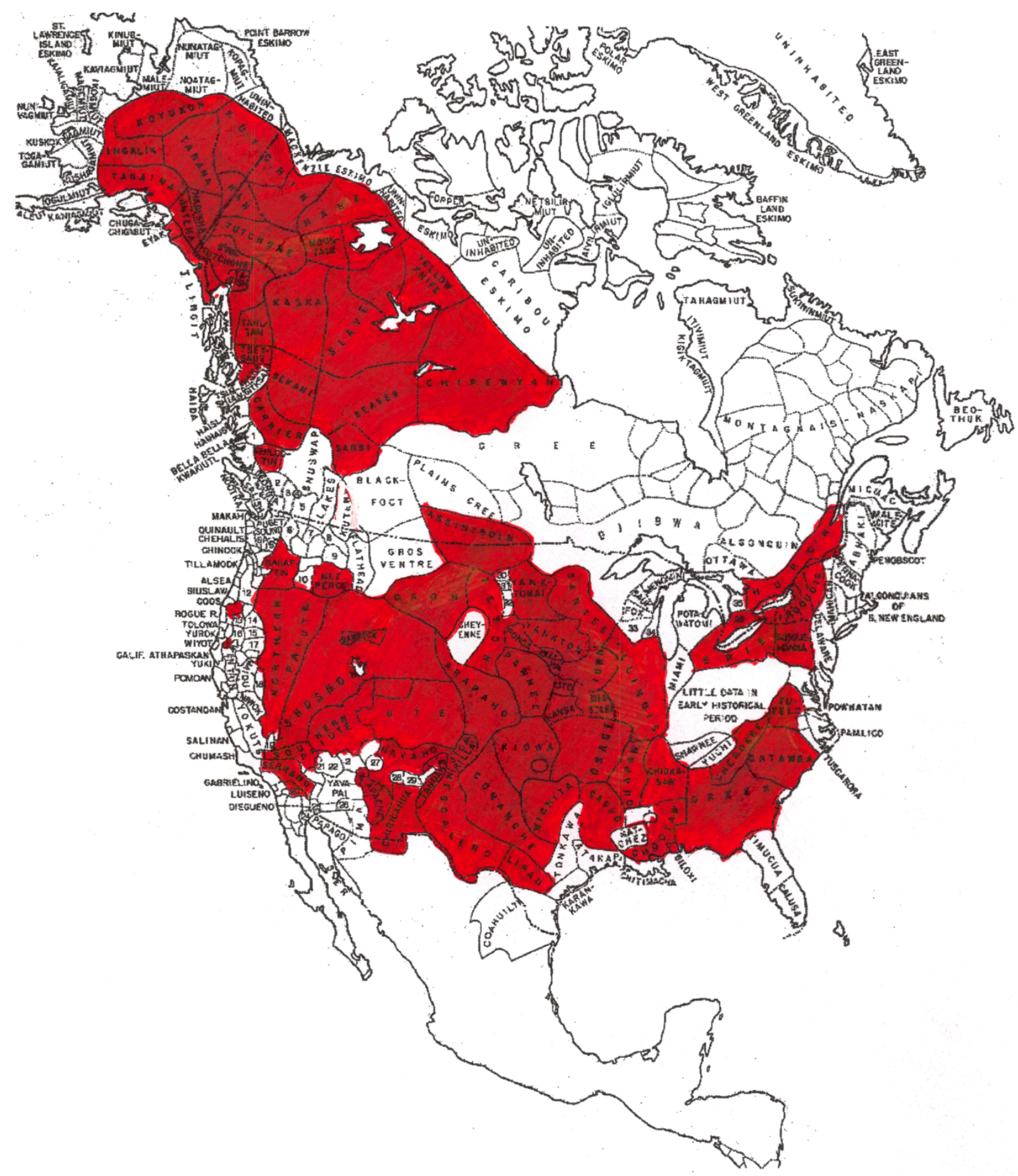

Figure 5. Noun Incorporation and Relicts

not related to any noun in the contemporary language. There is, for example, an independent noun name: $\check{5}$ 'fish'. Medials evoke such things as animals, body parts, environmental phenomena such as ice, snow, earth, trees, mountains, hills, rivers, etc, various foods, and useful objects, just like incorporated nouns. A smaller set of less than a dozen medials have more abstract meanings (stringlike, sheetlike, mineral, long and rigid, bound liquid, unbound liquid objects), again like 
some incorporated nouns that serve classificatory functions in other languages. Also like incorporated nouns, the medials are not arguments, and they alternate with independent nouns according to information structure. The medial constructions show the very beginning of a development of VERB-NOUN incorporating constructions to VERB-suffix constructions.

Other constructions developing along this route occur in certain linguistic areas of North America. The Salishan, Wakashan, and Chimakuan families of the Northwest Coast area all contain sizeable inventories of what are termed 'lexical suffixes', because of their often surprisingly concrete meanings, of the sort more often carried by roots in other languages. These languages show evidence of ancient, longstanding contact. They are typologically quite similar to each other. All are basically predicate-initial and show very weak differentiation of noun and verb roots.

In their 1994 dictionary of Lushootseed, a Salishan language spoken around the Puget Sound area in Washington State, Bates, Hess, and Hilbert list suffixes with meanings like the following: 'group viewed distributively'; 'breath'; 'parts of mouth'; 'body, bulky object, enclosed area'; 'people of'; 'tree, bush'; 'hair of head, crest, hackles of dog'; 'hand, forearm'; 'ear, side, sound'; 'trap'; 'along the base of the trees, among the trees at the base'; 'house, room, building'; 'testicles'; 'side of head'; 'year'; 'leg, hip'; 'house, some act being performed on a house'; 'odor'; 'place where something is kept'; 'clothes, clothing'; 'bundle, pack'; 'food'; 'hat'; 'tooth, straight pin'; 'domestic animal'; 'water'; 'shoulder'; 'eye, color'; 'paddle, animal hide'; 'meat'; 'bottom, base, buttocks'; 'throat, neck; forked'; 'at the side, edge, side appendage'; 'direction of water flow'; 'flame'; 'path, road'; 'homogenous group or cluster'; 'abdomen, belly'; 'baby, child'; 'clothe, wear, support from shoulder'; 'cover(ing), surface, on top of, over, series of items on a string, string cord, spine': 'torso, chest, breast'; 'ground, floor'; 'inside human or animal body, the insides, mental processes, inside small, tight-fitting area, side of body'; 'things, possessions'; 'shirt'; 'round thing, money, curved objects'; 'shank of leg'; 'incline, slope, bank, hill'; 'thigh'; 'nose, point'; 'foot including shank, entire leg and foot'; 'body of water to be crossed, river, mouth, language, doorway, opening in general, eat'; 'conference, parley, agenda'; 'container, belly'; 'land'; 'face, head upper part'; 'end, edge'; 'the very top'; and 'throat'.

The suffixes follow roots with both verb-like and noun-like meanings, and form words that serve as both predicates and referring expressions. The suffixes themselves are not strictly categorical, sometimes adding more noun-like meaning, sometimes more verb-like meaning. The construction does not specify their semantic relationship to the root: sometimes they indicate a general kind of patient/goal/theme, often a location. Their meanings are also not always as specific as might first appear. Examples of the suffix -ucid are in (8).

(8) Lushootseed (Salish) -ucid 'body of water to be crossed, river, mouth, language, doorway, opening in general, eat': Bates, Hess, and Hilbert 1994: 243

a. $\mathrm{d}^{\mathrm{z}}$ əl-úcid

reverse-body.of.water

'cross a river'

b. bəq'w-úcid

put.in.mouth-mouth

'kiss' 


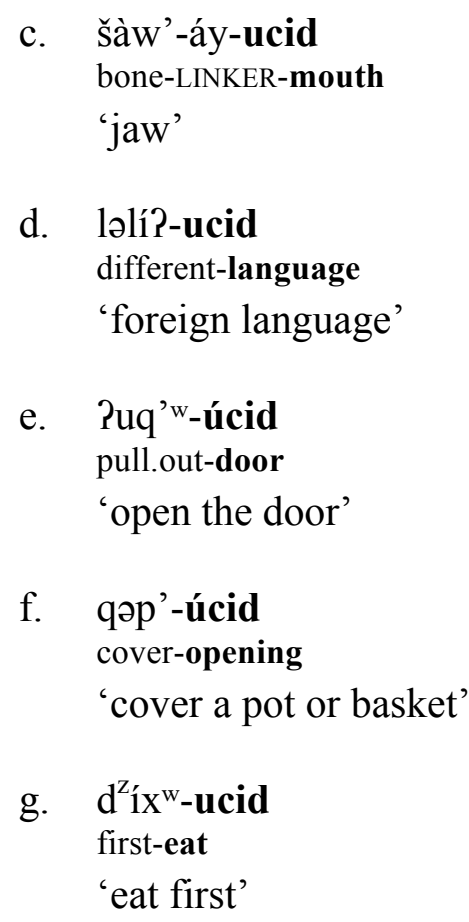

The suffixes tend to show more concrete meanings than would normally be expected of affixes, as well as less categoriality, features typical of grammaticalization processes. Like incorporated nouns in other languages, they often indicate kinds of themes, goals, sources, pathways, and locations. They were clearly already in place in Proto-Salishan.

To the west of the Salishan languages are languages of the Chimakuan family, Quileute and Chemakum, on the Olympic Penninsula at the extreme northwest corner of Washington State. Andrade (1933:194-198) lists large inventories of suffixes with similar meanings, 165 he considers more noun-like in meaning, 45 he considers more verb-like. They show such meanings as 'color'; 'weather'; 'wood'; 'food'; 'decorated blanket'; 'tree, log'; 'intestines, sinew'; 'stone arrowhead'; 'rock'; 'flounder'; 'navel'; 'nose'; 'point'; 'beach'; 'wall'; 'sky'; 'basket'; 'bow, gun, weapon'; 'plant, bush, tree'; 'bow'; 'leg, foot'; 'fish tail'; 'male anus'; 'female anus or buttocks'; 'skin', hide'; 'hat'; 'tooth'; 'forehead'; 'elbow'; 'day (used with numerals)'; 'gravel at bottom of sea'; 'footprints'; 'dress'; 'fishing equipment'; 'food to be eaten on a journey'; 'bowstring'; 'mind, heart'; 'dwelling, indoors'; 'breast, trunk, lungs'; 'village'; 'dead whale'; 'door'; 'breasts'; 'eye'; 'prairie'; 'place, location'; 'sealing canoe'; 'fishtrap'; 'bed'; 'hand, twig, branch'; 'odor'; 'tail of a quadruped'; 'vulva'; 'extreme, end'; 'eyebrow'; 'knife'; 'thigh'; 'manner, way'; 'territory'; 'wife'; 'river canoe'; 'whale'; 'fire (for warming or cooking)'; 'size, room'; 'river'; 'throat'; 'salmon egg'; 'body'; and 'own'; 'fishing in order to store it away'; 'have', 'need'; 'intend'; 'smell (intransitive)'; 'come from'; 'use' 'paddle'; 'arrive'; 'pack'; 'give'; 'catch fish in large quantities'; 'carry'; 'speak a language'; 'eat'; 'share with'; and many more. Andrade notes (1933:193-4) that in the vast number of cases, there is no formal resemblance between the suffixes and roots in the language with similar meaning, such as the word hae:tát and the suffix $-k$ ' $i$ 'arrow', and the word há 'ga: and the suffix $-y a$ 'tree'. He also notes that when both a word and a suffix exist, the suffix is generally more generic in meaning. There are several words for different types of canoes, for example, but the suffix $-q a$ is used for 
all of them. There are different words for 'bow', 'arrow', 'gun', and 'weapon', but all can be evoked by the suffix - $p a$. Their ranges of functions generally parallel those of the Salishan languages.

To the west of the Salishan languages and north of the Chimakuan languages are the languages of the Wakashan family. These, too, show large inventories of suffixes. Again, their meanings tend to be more general and disparate than their root counterparts, but more concrete and specific than what we normally expect of affixes. They show less categoriality. Their ranges of functions parallel those of their Salishan and Chimakuan neighbors, but their actual inventories differ in subtle ways.

Directly to the east of the Salishan languages in British Columbia, Idaho, and Montana, is the Kutenai language, generally considered an isolate. It too contains a set of lexical suffixes, with meanings and functions very similar to those in Salishan languages. They generally appear to be more noun-like than verb-like, and include many that evoke body parts. Eskimo-Aleut languages, which are not adjacent, also contain constructions which appear to be descended from noun-verb compounds. The modern languages are uniquely (or nearly) suffixing, but contain many complex bases consisting of an initial noun root followed by a verbalizing suffix with relative concrete meaning, such as 'eat', 'buy', 'catch', etc.

Figure 6 provides a general idea of the distribution of languages with lexical suffix constructions apparently descended from noun incorporation.

\subsection{Means/Manner/Instrumental affixes}

Another strong linguistic area shows special patterns of morphological elaboration that go beyond genetic borders. Communities indigenous to Northern California and neighboring areas of modern Oregon, Idaho, and Nevada were always small and generally exogamous. Multilingualism was the norm. Children often grew up with parents who spoke different languages. So far as is known, there were no significant differences in prestige among the languages; it was simply considered polite to speak the language of the community one was in (Conathan 2004, O’Neill 2008, Jany 2009, Mithun 2010, Haynie 2012, Spence 2013). Bilinguals consciously choosing to speak one of their languages would presumably pay attention to features they were most conscious of, carefully selecting vocabulary from that language. But they might easily transfer a propensity to specify certain distinctions from one of their languages to the other. Bilinguals accustomed to mentioning the source and/or reliability of information (evidentiality) in one language, for example, might mention it more often in another, even if that meant using analytic constructions: 'it is said that', 'it appears that', . . . And frequency of expression is the foundation for the development of grammatical structure. Not surprisingly, we find areal elaboration of evidential distinctions. In Northern California, for example, the Palaihnihan languages contain verb prefixes for hearsay, inference, and general knowledge; Shasta prefixes distinguish direct experience, inference, and reportative sources; Washo distinguishes visual evidence, auditory evidence, and inference; Wintu distinguishes knowledge acquired from direct experience, hearsay, other hearing, touch, smell, taste, and inference. The Pomoan languages distinguish personal experience, hearsay or reportative evidence, other aural evidence, factive statements (everyone knows that), inference, performative evidence (I know because I did it myself), and affective evidence (I know because it affected me). 


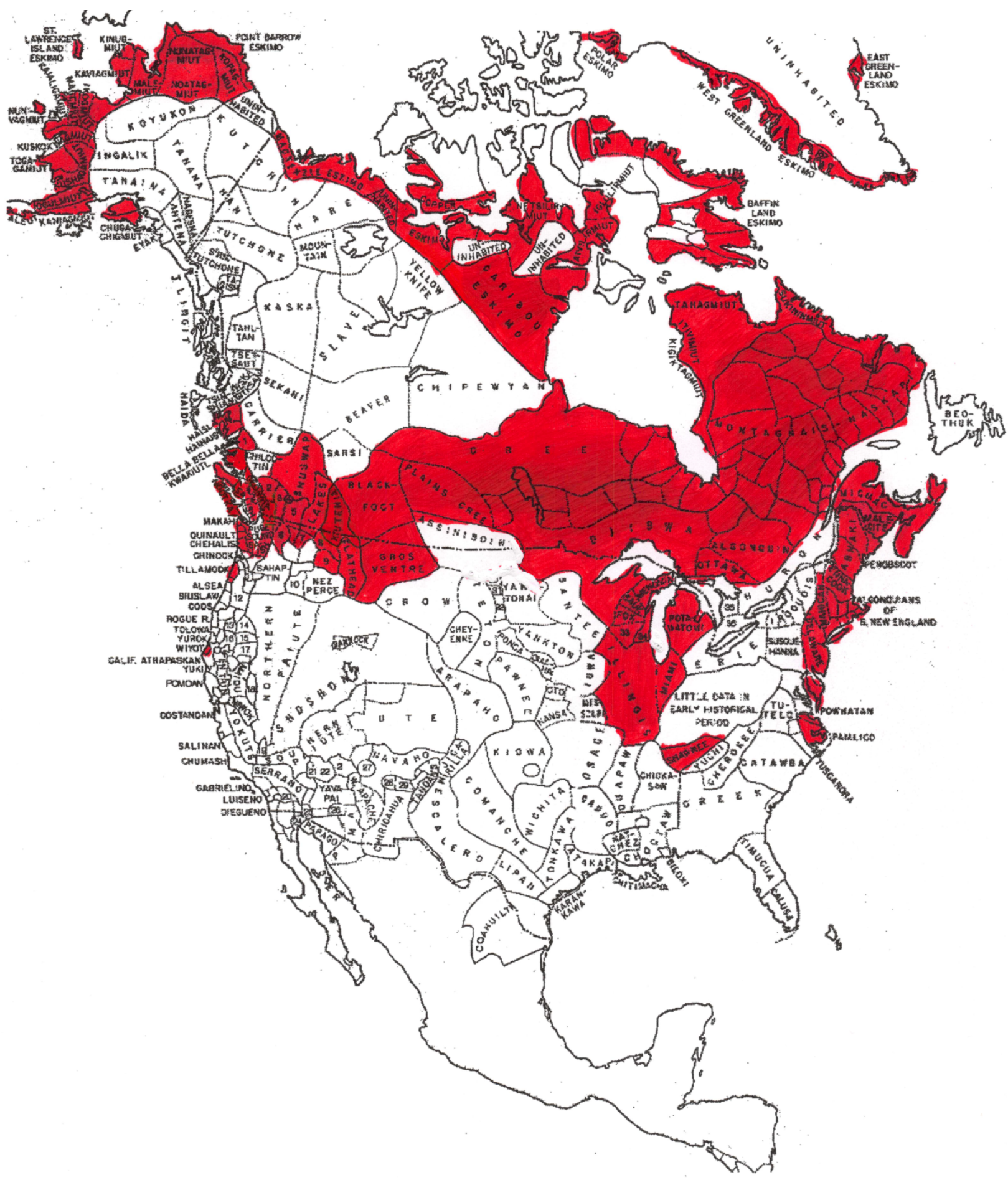

Figure 6. Descendants of Noun Incorporation: Lexical Affixes

A large number of languages in the West contain verbal prefixes indicating a kind of means or manner of motion, sometimes referred to as 'instrumental prefixes' (Mithun 2007). Jansen provides examples from Yakima Sahaptin with the verb root - $t t^{\prime} k i$ 'break'. 
(9) Yakima Ichishkíin Sahaptin: Jansen 2010: 234
a. pá-tł'k-
hand-break
'break apart'
b. wáx̣-ty'k-
chop-break
'chop off'
c. chá-tł'k-
teeth-break
'bite in two'
d. súx̣-tł'k-
pole-break
'pry apart'
e. x̣úl-tl'k-
ground-break
'break by lying on'
f. sháx̣-tł'k-
knife-break
'cut or saw apart'

As Jansen notes, the meanings of the prefixes are actually not as specific as their glosses might first suggest. They often indicate as much a manner of motion as a specific instrument. She cites the prefix $t w a$-, which indicates not simply involvement of a long instrument, but one held by a handle, at an angle, moved radially, in the way that one writes, stirs batter, scrapes a hide, or shaves.

(10) Yakima Ichishkíin Sahaptin: Jansen 2010:235

$\begin{array}{ll}\text { twá-lii- } & \text { 'fish by dipnet' } \\ \text { twá-pxw- } & \text { 'scatter with a long instrument' } \\ \text { twá-k'aatk- } & \text { 'scrape, shave' } \\ \text { twá-k'ilk- } & \text { 'mix, stir' }\end{array}$

The prefixes show blurred categoriality: a prefix might as well be glossed 'with knife' as 'by sawing'. Among the prefixes listed by Jansen are some glossed 'with teeth, pulling, biting, lifting'; 'rolling'; 'with mouth, eating, tasting'; 'with fire, heat, light, smoke'; 'hearing, with the ear'; 'carrying, lifting'; 'with hands, pushing, pushing with upper part of the body'; 'with knife, scissors, plane, cutting, scraping'; 'crawling, on all fours'; 'with knife, slicing vertically or horizontally, plow'; 'with pole, needles, prying or pushing'; 'by shooting, power, with extra force, missile, arrow'; 'by throwing', 'with butt, anus, backwards'; 'while walking'; 'lower arm, hand, toes'; 'stick, cane, vertical movement up and down'; 'with foot, by kicking'; 'with head, 
butting motion'; 'with pointed implement, point, end'; 'with long implement, radial motion, as writing, shaving, golfing'; 'with instrument, chopping motion as when using an axe, hammer'; 'circling and tying something around'; 'eye motion, seeing'; 'paddling, in canoe'; 'with speed'; 'with movement'; 'falling'; 'reclining'; 'water'; and 'in fear'. (Jansen 2010:236-8)

Inventories of such prefixes are pervasive throughout the West, crossing genetic boundaries. Means/manner prefixes with very similar meanings recur in language after language. Yakima Sahaptin is a member of the Sahaptian family, which includes other Sahaptin varieties and Nez Perce. All show such prefixes. The Sahaptian family was once grouped into a superstock termed "Penutian", based to some extent on structural similarities. Other families grouped into this superstock also show such prefixes: those of the Maidun family (Maidu, Konkow, Nisenan), Klamath, and Takelma. But they do not appear in other "Penutian" languages, such as those of the Wintun, Utian, and Yokutsan families of California, or Coos, Siuslaw, and Alsea in Oregon, or others further afield.

Such prefixes also occur in languages of the area once hypothesized to be part of an entirely different superstock, "Hokan": languages of the Pomoan family (Northern Pomo, Central Pomo, Southern Pomo, Northeastern Pomo, Southeastern Pomo, and Kashaya, all in Northern California), languages of the Palaihnihan family (Achumawi and Atsugewi, in Northern California), languages of the Chumashan family (Obispeño, Purisimeño, Ineseño, Barbareño, Ventureño, and Cruzeño, on the Central California coast), and languages of the Yuman-Cochimi family (Iipay, Kumeyaay, Tiipay, Cocopa, Yuma, Maricopa, Mojave, Upland Yuman, Paipai, Kiliwa, Cochimi in Southern California and into western Arizona), as well as in Karuk and Yana in Northern California, and Washo in adjacent Nevada. But such prefixes do not appear in other languages grouped as "Hokan", such as Shasta, Esselen, and Salinan.

The precise inventories of prefixes vary across the languages, but their functions are strikingly similar. They are word-formation devices, so their meanings can often only be assessed from the verbs in which they occur. Talmy (1972: 407-427) lists a number of prefixes for Atsugewi, with the kinds of verbs in which they are found. As in the other languages, the prefixes show blurred categoriality, evoking both kinds of instruments and kinds of actions: $t u$ 'hands, working towards each other'; $c i$ - 'hands working manipulatively'; $m a$ - 'feet', $t i$ 'buttocks'; wi- 'teeth'; pri- 'mouth interior, sucking, tasting, smelling'; phu- 'mouth interior, spitting, blowing'; - 'mouth exterior'; uh- 'arm, swinging, batting, throwing, pounding, chopping, sailing, load, falling into, as hailstone, snow on limb, falling, spread out blanket, board nailed to wall'; $c u$ - 'linear object moving axially, pool-cueing, prodding, pushing steadily with stick, poking, piercing, skewering, holding pinned against a wall, supporting with a cane'; $r a$ 'thrusting up at an angle, digging, awling, sewing, propping, leaning, poling, raking, sweeping, scraping, smoothing over, whittling, plowing, hugging, scoring, slicing, sawing, driving, steamrolling, getting run over, gas in stomach, ice under soil, leaning cradleboard, shingle'; ta'paddling (hot rock in soup), stirring'; $k a$ - 'boring, rain'; ru- 'dragging with cord, flexing (one's muscle), suspending with cord, binding, girding, sinew, belt, unerect penis, icicle'; mi- 'knife, cutting'; ca- 'wind blowing'; $c u$ - 'liquid flowing, car in collision'; miw-/mu- 'heat, fire'; $w u$ 'light shining on figure'; $s a-/ s u$-/si-/siw- 'visually'; $k a-/ k u$-/ ki-/kiw- 'aurally', tu- 'touching'; cri'hairs in a braid, stalks in a sheaf, sticks in a bundle';

The prefixes occur in a third group as well, consisting of the Wappo and Yuki languages, both in Northern California adjacent to the Pomoan languages. They also occur in a fourth group, by all accounts unrelated to any of the previous three. The Uto-Aztecan family consists of over 30 languages spoken from Idaho to El Salvador, and California to Oklahoma. The means/manner 
prefixes occur in just one branch of the family, however, Numic, whose speakers are in the Great Basin in eastern California, Oregon, Idaho, and into Utah and Wyoming.

The languages vary in their inventories of prefixes and the transparency of their meanings, though certain meanings appear in language after language. In some languages the inventories are quite small, often only a single consonant, with relatively vague meanings. Others show much larger inventories, with large proportions of verb stems containing elements indicating means/manner/involvement. Often the contribution of the prefix is somewhat obscure; stems were formed one by one by analogy to existing vocabulary, often metaphorically. In some languages, particularly those located at the periphery of the area, sources of some of the prefixes can be seen in surviving noun or verb roots. For Yakima, Jansen notes that the etymological sources of most of the prefixes are no longer discernible; most bear no resemblance to an independent noun indicating a body part or other object. She does note a few, however: pá- 'with hand', resembling ipáp 'hand, arm', and msh- 'with ear', resembling mishyú 'ear' (Jansen 2010:239).

The development of means/manner/instrumental affixes from compounds containing an instrument noun or manner verb is not entirely surprising. Compounds with these structures are not unusual, nor is the evolution of bound roots to affixes. Such prefixes occur in several areas of North America: not only California and adjacent areas, but also in the isolate Haida on the northern Northwest Coast, in the Siouan family, which extends over the Plains from north of the Canadian border to the Gulf of Mexico. Kutenai has a set of similar suffixes. The concentration of means/manner prefixes in California and its neighbors suggests contact factors at work, however. It appears that the constructions originated in a propensity to specify means/manner often as the first root of a compound. This propensity apparently spread from California outward: languages at the center of the area generally have shorter forms, sometimes just a single consonant, often with more abstract and diffuse functions and no discernible lexical sources, while those at the periphery show larger forms with somewhat clearer, more concrete meanings, some with surviving root origins, and in some cases surviving compound constructions in which the initial noun or verb stem indicates a means or manner of motion.

Figure 7 provides an idea of the distribution of the means/manner affixes. Together, noun incorporation, relicts of noun incorporation, and derivational descendants of noun incorporation cover a wide area of North America, as illustrated in Figure 8. In fact, languages with no trace of noun incorporation or its descendants are few and far between, as illustrated in Figure 9.

In sum, the flourishing of morphologically complex constructions like noun incorporation and its descendants could be facilitated by a preponderance of small communities of intimates: incorporation can produce large inventories of complex verb stems in the common lexicon of speakers who interact frequently. Areal concentrations of certain types of morphological elaboration suggest that language contact may play a role as well. In addition to the lexical suffixes of the Northwest Coast and the means/manner/instrumental prefixes of the California linguistic area, there are, for example, concentrations of locative/directional suffixes in the California area (DeLancey 1996, Mithun 2010). Of all morphological structures, compounding should particularly susceptive to replication under situations of language contact, not far removed from the replication of idiomatic turns of phrase. Compounding is a process that is already pervasive cross-linguistically, so it would not necessarily be novel in the first place. The elements, full stems (or words), still generally have their full phonological substance early on, and relatively concrete meanings. What might be replicated by bilinguals would be a propensity to specify certain distinctions, and particular patterns of compounding, such as instrument-root. 


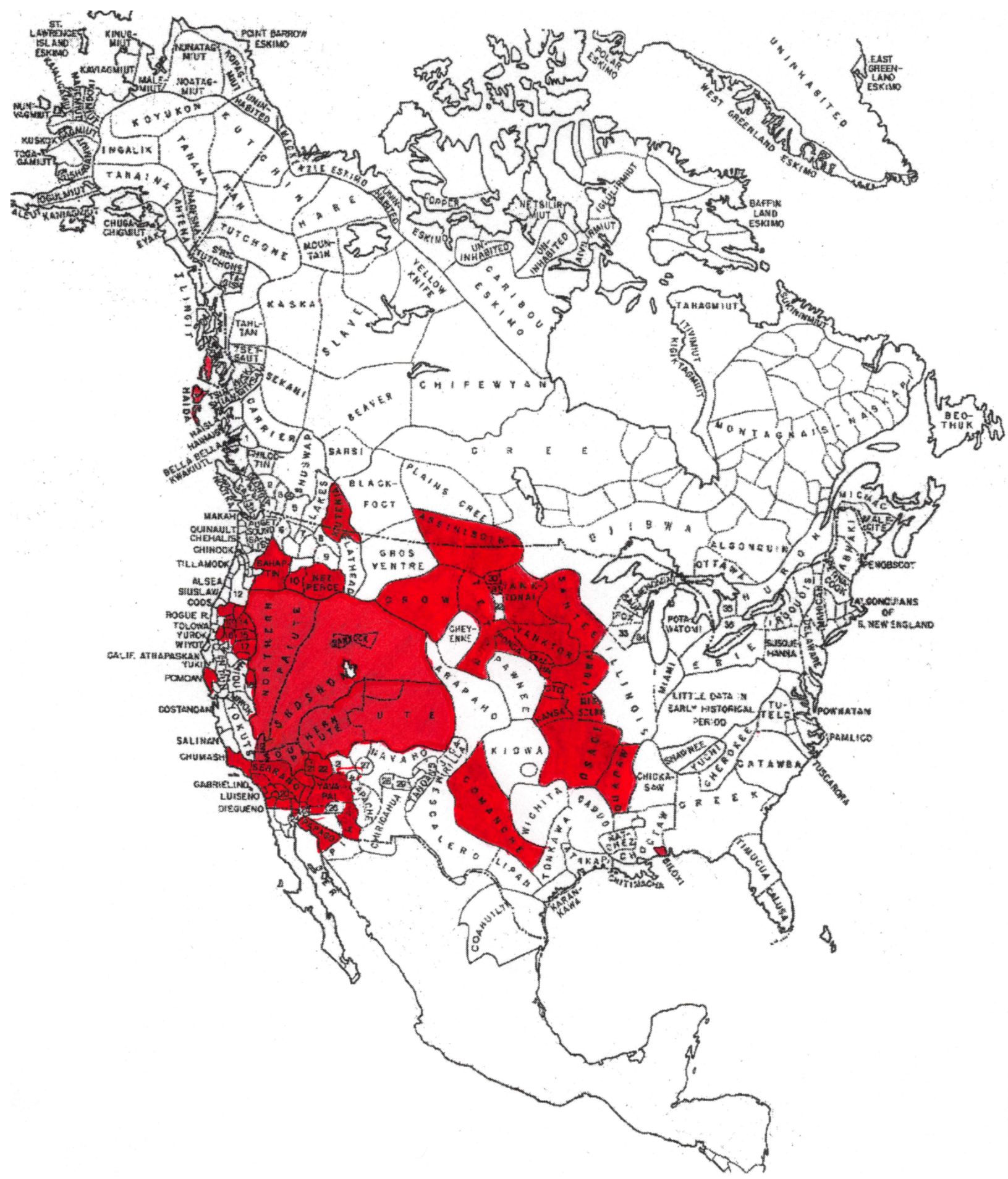

Figure 7. Means/Manner/Instrumental Affixes 


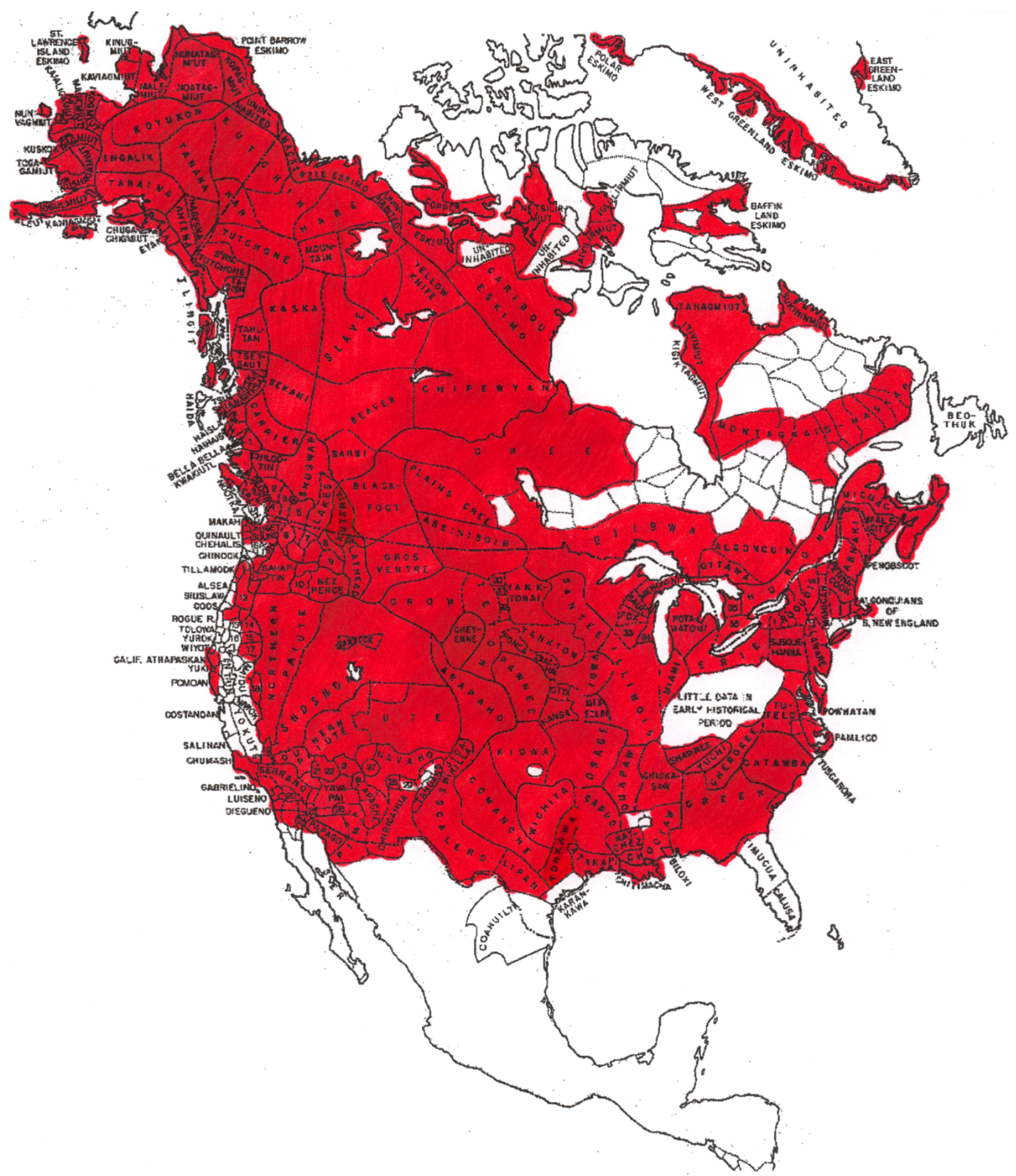

Figure 8. Languages with Incorporation or Descendants of Incorporation 


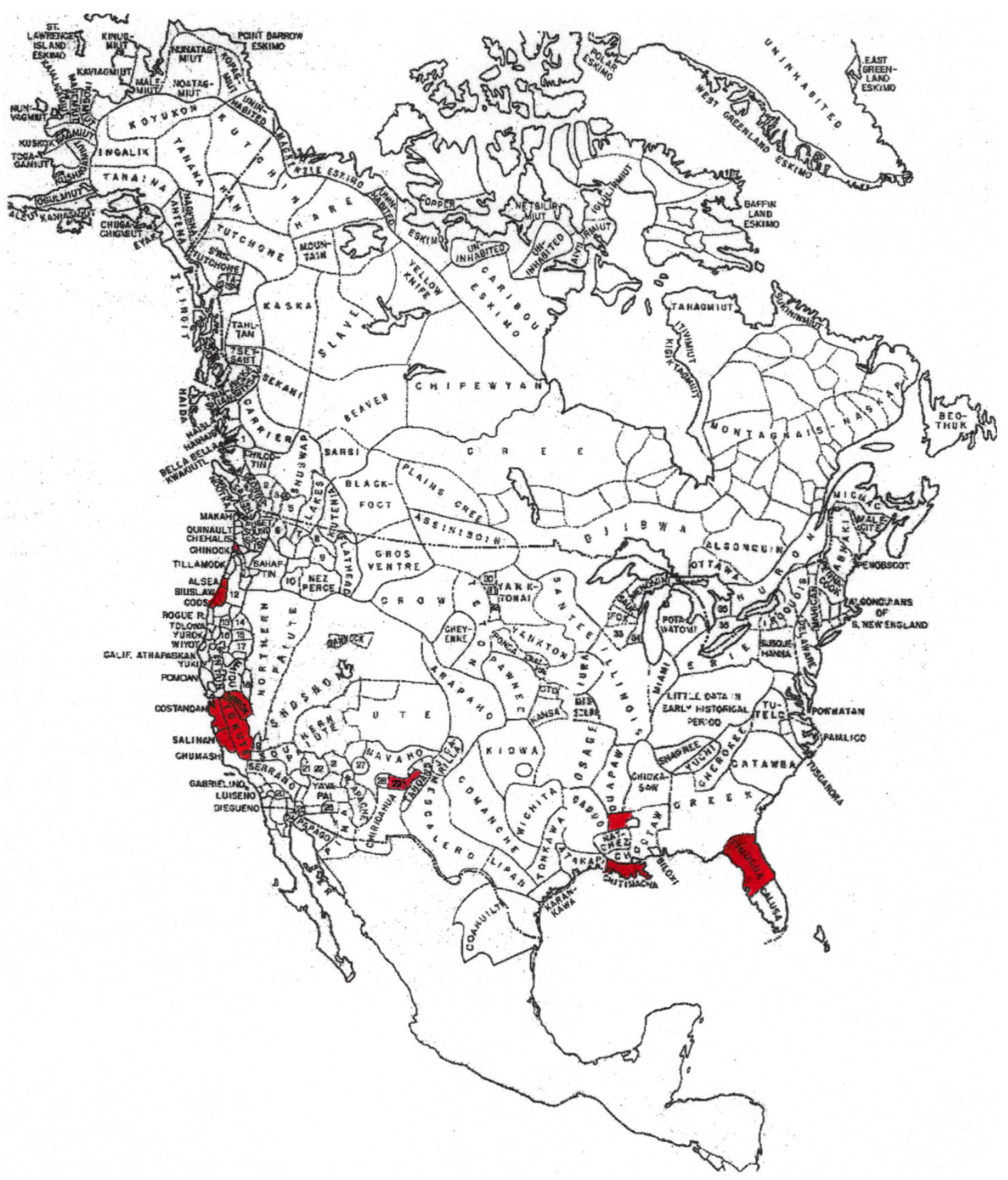

Figure 9. Languages with No Trace of Noun Incorporation or its Descendants

\section{Conclusion}

At least two major kinds of factors can be hypothesized to underlie some of the morphological complexity typical of North America. The widespread existence of pronominal affixes for all core arguments and the sizeable sets of affixes with relatively concrete and specific meanings (though not as concrete and specific as roots) in different areas suggest that there might be general factors at play in their development: as suggested by Trudgill and Dahl, long periods of development, probably from compound constructions to affix constructions, unhampered by the 
simplifying tendencies of large populations of adult second-language speakers. But subtle differences in the inventories and functions of the affixes in the different areas suggest a second. It appears that early contact, at the compounding stage or before, affected propensities for expressing certain distinctions in everyday talk. Bilinguals accustomed to elaborate expression of certain features in one language presumably carried frequencies of expression into their other language, frequencies which would lay the groundwork for the development of the particular affix constructions we find today.

\section{References}

Andrade, Manuel 1933. Quileute. Extract from the Handbook of American Indian Languages 3:151-292. New York: Columbia University Press.

Bates, Dawn, Thom Hess, and Vi Hilbert 1994. Lushootseed Dictionary. Seattle: University of Washington Press.

Brinton, Daniel G. 1886. On polysynthesis and incorporation as characteristics of American languages. Proceedings of the American Philosophical Society 23.121:48-86.

Conathan, Lisa 2004. Linguistic ecology of Northwestern California: Contact, functional convergence and dialectology. Ph.D. dissertation in linguistics, University of California, Berkeley.

Dahl, Östen 2004. The Growth and Maintenance of Linguistic Complexity. Amsterdam: Benjamins.

Dahl, Östen To appear. Polysynthesis and complexity. The Oxford Handbook of Polysynthesis. Nicholas Evans, Michael Fortescue, and Marianne Mithun, eds. Oxford, UK: Oxford University Press.

DeLancey, Scott 1996. Penutian in the bipartite stem belt: Disentangling areal and genetic correspondences. Proceedings of the 22nd Annual Meeting of the Berkeley Linguistics Society: Special Session on Historical Topics in native American Languages. 37-54.

Drapeau, Lynn 2014. Grammaire de la langue innue. Quebec: Presses de l'Université du Québec.

Duponceau, Peter Steven 1819. Report of the corresponding secretary to the Committee, of his progress in the investigation committed to him of the general character and forms of the languages of the American Indians. Read 12th January, 1819. Transactions of the Historical and Literary Committee.

Dyk, Walter 1933. A Grammar of Wishram. Ph.D. dissertation, Yale University.

Feeling, Durbin 1975. Cherokee-English Dictionary. William Pulte, ed. Tahlequah, OK: Cherokee Nation of Oklahoma.

Fortescue, Michael, Steven Jacobson, and Lawrence Kaplan 2010. Comoparative Eskimo dictionary with Aleut cognates. 2nd ed. Fairbanks, AK: Alaska Native Language Center.

Graczyk, Randolph 2007. A Grammar of Crow. Lincoln, NB: University of Nebraska Press.

Haynie, Hannah 2012. Topics in the history and geography of California languages. Ph.D. dissertation in linguistics, University of California, Berkeley.

Hewitt, J.N.B. 1893. Polysynthesis in the languages of the American Indians. American Anthropologist 6:381-408.

Jansen, Joana 2010. A Grammar of Yakima Ichishkiin/Sahaptin. Ph.D. dissertation, University of Oregon. 
Jany, Carmen 2009. Chimariko grammr: Areal and typological perspective. University of California Publications in Linguistics 142. Berkeley: University of California.

Kusters, Wouter. 2003. Linguistic complexity: the influence of social change on verbal inflection. Utrecht: LOT Publications.

Kusters, Wouter 2008. Complexity in linguistic theory, language learning and language change. Language Complexity: Typology, Contact, Change. Matti Miestamo, Kaius Sinnemäki \& Fred Karlsson eds.,23-41. Amsterdam \& Philadelphia, PA: John Benjamins.

Linsdröm, Eva 2008. Language complexity and interlinguistic difficulty. Language Complexity: Typology, Contact, Change. Matti Miestamo, Kaius Sinnemäki \& Fred Karlsson eds., 217235. Amsterdam \& Philadelphia, PA: John Benjamins.

Miestamo, Matti 2008. Grammatical complexity in a cross-linguistic perspective. Language Complexity: Typology, Contact, Change. Matti Miestamo, Kaius Sinnemäki \& Fred Karlsson eds., 23-41. Amsterdam \& Philadelphia, PA: John Benjamins.

Mithun, Marianne 2007. Grammar, contact, and time. Journal of Language Contact. (e-journal) THEMA 1:133-155. www.jlc-journal.org

Mithun, Marianne 2010. Contact in North America. Handbook of Language Contact. Raymond Hickey, ed. Oxford: Blackwell. 673-694.

Mithun, Marianne In press. Affix ordering: Motivation and interpretation. The Cambridge handbook of morphology. Andrew Hippisley and Gregory Stump, eds. Cambridge, UK: Cambridge University Press.

Mithun, Marianne To appear a. Polysynthesis in North America. Handbook of Polysynthesis, Nicholas Evans, Michael Fortescue, and Marianne Mithun, eds. Oxford, UK: Oxford University Press.

Mithun, Marianne To appear b. The marking of arguments in the polysynthetic verb and its implications. Handbook of Polysynthesis, Nicholas Evans, Michael Fortescue, and Marianne Mithun, eds. Oxford, UK: Oxford University Press.

O'Neill, Sean 2008. Cultural contact and linguistic relativity among the Indians of Northwestern California. Norman: University of Oklahoma Press.

Sapir, Edward 1922. The Takelma language of southwestern Oregon. Handbook of American Indian Languages Part 2. Franz Boas, ed. Smithsonian Institution Bureau of American Ethnology Bulletin 40. Washington D.C.: Government Printing Office. 1-296.

Spence, Justin 2013. Language change, contact, and koineization in Pacific Coast Athabaskan.Ph.D. dissertation in linguistics, University of California, Berkeley.

Talmy, Leonard 1972. Semantic Structures in English and Atsugewi. Ph.D. dissertation, University of California, Berkeley.

Trudgill, Peter To appear. The Anthropological Setting of Polysynthesis. The Oxford Handbook of Polysynthesis. Nicholas Evans, Michael Fortescue, and Marianne Mithun, eds. Oxford, UK: Oxford University Press. 